\title{
O olhar da assistência social na construção da política indigenista no Brasil
}

\section{The look at social assistance in the construction of indigenous policy in Brazil}

Natália Raquel Niedermayer - Mestre em Extensão Inovadora e Desenvolvimento Rural Sustentável, pela Universidade Estadual do Oeste do Paraná (UNIOESTE). E-mail: natalia.niedermayer@gmail.com

Marli Roesler - Doutorado em Serviço Social, pela Pontifícia Universidade Católica de São Paulo (PUC/SP). Professora associada da Universidade Estadual do Oeste do Paraná (UNIOESTE).E-mail: marliroesler@hotmail.com

\section{Resumo}

O presente trabalho tem como objetivo apresentar elementos sobre a construção da política indigenista no Brasil, com ênfase no município de Guaíra-PR, aproximando avanços e contradições marcadas por resistências e lutas históricas e atuais dos povos indígenas como o direito ao território, à demarcação da terra, de proteção às culturas tradicionais de diversas etnias e respeito ao protagonismo que lhe é inerente e inalienável. Nessa realidade, que suscita a observação de categorias próprias e intervenções no movimento da sociabilidade e do mundo humano, de defesa de igualdades e não violações de direitos numa perspectiva universalista, se insere a intervenção da(o) profissional assistente social, corresponsável pela leitura crítica, propositiva e alternativa às políticas sociais no movimento histórico e quotidiano, de mediações que se diferenciam de práticas integracionistas, tutelares e desiguais, materializadas e instrumentalizadas na política indigenista no Brasil.

\section{Palavras-chave}

Política indigenista. Assistência social. Extensão universitária. Serviço social.

\begin{abstract}
The present work aims to present elements on the construction of indigenous politics in Brazil, with emphasis on the municipality of Guaíra-PR, bringing together advances and contradictions marked by historical and current resistance and struggles of indigenous peoples, such as the right to territory, the demarcation of land, protection of the traditional cultures of various ethnic groups and respect for the inherent and inalienable protagonism. In this reality, which raises the observation of own categories and interventions in the movement of sociability and the human world, of defense of equality and non-violation of rights in a universalist perspective, the intervention of the professional social worker, responsible for critical reading, propositional and alternative to social policies in the historical and daily movement, mediations that differ from integrationist, tutelary and unequal practices, materialized and instrumentalized in the indigenist policy in Brazil.
\end{abstract}

\section{Keywords}

Indigenous policy. Social assistance. University extension. Social work. 


\section{INTRODUÇÃO}

Pensar em política indigenista é entender que a garantia do direito dos povos indígenas dar-se-á por meio do reconhecimento do território de vida, da demarcação das terras e de proteção das culturas tradicionais ${ }^{1}$. É buscar saber quem são esses povos protagonistas, em quais espaços participativos e democráticos se encontram, é identificar seus costumes, tradições nativas, vulnerabilidades e potenciais, compreender e respeitar as formas de organizações econômicas, sociais, territoriais, ambientais e sua estrutura social para buscar o desenvolvimento de uma visão complexa e universal sobre os direitos coletivos desses povos. É preciso identificar as resistências e lutas atuais contra as desigualdades sociais, construir outra perspectiva de sociabilidade, redimensionar a construção da política indigenista e intersetorialidade com demais políticas públicas, com sentidos reais e verdadeiros aos dos povos indígenas.

A partir da perspectiva crítica, formulamos este trabalho que tem como objetivo central apresentar contribuições sobre a construção da política indigenista. Deste modo, compreendemos as políticas sociais como produto histórico que assumem no capitalismo monopolista, por sua dinâmica e contradições, condições propícias para que o Estado busque legitimidade política por meio do jogo democrático, permeável também às demandas das classes subalternas, que podem influenciar os interesses e suas demandas imediatas (PAULO NETTO, 1996).

Dentre as políticas sociais, o presente trabalho dá maior ênfase à política da assistência social, campo em que o governo vem buscando abranger os povos indígenas nos programas de transferência de renda, como o Programa Bolsa Família e o Fome Zero, com distribuição de cestas básicas, ações de caráter emergencial e investimentos em produção sustentável de alimentos, por meio do Programa Carteira Indígena, desenvolvido em parceria com o Ministério do Meio Ambiente.

Ainda consideramos neste trabalho, um breve relato sobre Projeto de Extensão "Ações Socioambientais em defesa dos direitos dos povos indígenas na

\footnotetext{
"É importante ressaltar que a demarcação é um ato secundário. Ainda que a terra indígena não esteja demarcada, o fato de existir ocupação tradicional já é suficiente para que as terras sejam protegidas pela União" (MARÉS, 2013, p. 174)

"A terra indígena se define não pela demarcação, mas pela ocupação indígena, como dispõe a Constituição. [...] A Constituição ordenou à União que demarque as terras indígenas com a finalidade de proteger e respeitar os bens de cada povo. Está claro que o direito sobre as terras independe desta demarcação, que é mero ato administrativo de natureza declaratória" (MARÉS, 2013, p. 24)
} 
aldeia Tekohá Yhovy", no município de Guaíra-PR, desenvolvido conjuntamente pelo Programa de Educação Tutorial (PET) do curso de Serviço Social da Universidade Estadual do Oeste do Paraná, campus de Toledo, identificando os desafios e os objetivos alcançados.

\section{O DESAFIO PARA A FORMULAÇÃO PARTICIPATIVA DA POLÍTICA INDIGENISTA}

O Estado brasileiro começou a dar respostas a essas demandas que tratam da formulação de uma política indigenista por volta do ano de 1910, com a criação do Serviço de Proteção ao Índio (SPI). O SPI foi um órgão administrado pelo governo federal em um momento que ainda predominavam antigas ideias evolucionistas sobre a humanidade e o seu desenvolvimento por estágios, tendo como base uma ideologia etnocêntrica e nas teorias raciais que marcaram o século XIX até o início do século XX. Em meio a isso, o ordenamento jurídico vigente nesse período considerava os índios como indivíduos incapazes, estabelecendo assim, uma figura jurídica com o objetivo de tutela e incorporando a assimilação forçada desses povos a sociedade nacional, não respeitando a garantia da reprodução física e cultural dos povos indígenas (FUNAI, s/d).

Com a extinção do SPI, devido a denúncias de corrupção, foi criada a Fundação Nacional do Índio (FUNAI), no ano de 1967. Na década de 1980, com o processo de redemocratização do Estado brasileiro e, posteriormente, com o advento da CF 1988, a política indigenista sofreu mudanças conceituais (como, por exemplo, o termo autodeterminação) e jurídicas por meio da ampliação dos espaços de formulação dessas políticas, garantindo a participação do povo indígena na auto-organização política. Nesse sentido, buscou-se extinguir o caráter de tutela das políticas para a afirmação da autonomia dos povos e a necessidade de respostas mais efetivas do Estado. Diante desse processo de redemocratização, Terena (2013) aponta que a política indigenista deve estar institucionalizada a partir de novos parâmetros de desenvolvimento de médio e longo prazo, executada e concentrada numa agência que tenha forças políticas, com status de ministério e que seja capaz de responder as demandas dentro de um plano de metas com objetivos, prazos e resultados compatíveis (TERENA, 2013).

No ano de 2009, ocorreu a reestruturação da FUNAI a partir do Decreto n⿳o 7.056, anunciando mudanças na gestão do órgão e dividindo as responsabilidades 
presidenciais. No entanto, esse decreto gerou graves conflitos com os indígenas por ser um decreto construído de forma arbitrária sem consulta prévia aos povos indígenas que seriam diretamente afetados, já que o próprio decreto prevê o fechamento de 24 das cerca de 50 administrações regionais do órgão indigenista e de todos os postos indígenas no país, ocorrendo um grande distanciamento entre a FUNAI e os povos indígenas (BRASIL, 2007, s. p.).

No ano de 2017, uma nova reestruturação da FUNAI, pelo Decreto no 9.010, causou impactos negativos na realidade dos povos indígenas, extinguindo 87 cargos comissionados. Os escritórios regionais, as áreas responsáveis pelas demarcações e pela análise do licenciamento ambiental de obras que atuam nas Terras Indígenas foram as mais atingidas. Foram extintos 51 cargos da Coordenação Técnica Local, tendo impactos imediatos sobre a proteção dos territórios e atendimentos às populações indígenas tendo em vista que esses servidores eram os principais interlocutores com as comunidades indígenas. $\mathrm{O}$ Estatuto da FUNAI, no artigo $2^{\circ}$, prevê, entre outros, a garantia e a promoção dos direitos sociais aos povos indígenas, por meio da participação desses povos e de suas representações nos espaços que definem suas políticas públicas.

Diante do que prevê o Estatuto, a atuação da FUNAI firma-se no entendimento de que as políticas sociais devem necessariamente prever ações indigenistas que assegurem em suas ações o respeito e a promoção das especificidades socioculturais e territoriais dos povos indígenas, por meio do controle social e da participação indígena, de modo a garantir intervenções nos espaços institucionais de diálogo entre os diversos sujeitos que atuam no campo do indigenismo e nos processos de formulação das políticas públicas (FUNAI, 2013).

Com o objetivo de estruturar e garantir espaços de decisão que promovam a participação indígena foi criado o Conselho Nacional de Política Indigenista pelo Decreto $n^{-}$8.593, de 17 de dezembro de 2015, no âmbito do Ministério da Justiça. Esse novo Conselho garante maior representatividade de órgãos do poder executivo federal, representantes de povos e organizações indígenas em todas as regiões (de 20 para 28 representantes), sendo responsáveis pela elaboração, acompanhamento e implementação de políticas públicas, voltadas aos povos indígenas (FUNAI, 2015, s. p.).

A construção e realização da 1 a Conferência Nacional de Política Indigenista, realizada de 17 a 20 de novembro de 2015, em Brasília, com o tema "A relação do Estado Brasileiro com os Povos Indígenas no Brasil sob o paradigma 
da Constituição de 1988", também representou um grande avanço em relação à participação dos povos indígenas. As 866 propostas construídas em etapas locais e regionais, aprovadas na Conferência, demonstram, mais uma vez, a necessidade de políticas mais efetivas e um posicionamento mais sério e comprometido do Estado brasileiro. De qualquer modo, construir uma conferência sobre políticas indigenistas, na atual conjuntura, demonstra sinais de avanços e apresenta-se, mais uma vez, como uma forma de resistência dos povos indígenas na busca pela proteção dos seus direitos.

\section{ESPECIFICIDADESDASPOLÍTICASSOCIAISNAINTERVENÇÃO DO SERVIÇO SOCIAL E ÁREAS INTERDISCIPLINARES}

A criação do Ministério de Desenvolvimento Social e Combate à Fome (MDS) e a Política Nacional de Assistência Social (PNAS), em 2004, foram os pontos de partida para o governo federal desenvolver ações direcionadas para os indígenas, visando o combate à extrema pobreza. No ano de 2005, esse tema foi discutido na V Conferência Nacional de Assistência Social, em uma oficina específica, que abordou a discussão sobre a organização da Proteção Social Básica em comunidades indígenas e quilombolas. No ano seguinte, com objetivo de dar sequência à essa discussão, o Conselho Nacional de Assistência Social criou um grupo de trabalho para discutir o tema "comunidades indígenas e quilombolas" (BRASIL, 2007, s. p.).

De acordo com o Ministério do Desenvolvimento Social e Combate à Fome (BRASIL, 2016), o Sistema Único de Assistência Social (SUAS) possui 21 Centros de Referência de Assistência Social (CRAS) com atendimento exclusivo dentro das aldeias indígenas. A Rede SUAS conta ainda com 240 Centros de Referência Especializado de Assistência Social (CREAS) e 574 CRAS que estão em territórios que atendem comunidades indígenas, mas que não são exclusivos. Todos esses equipamentos são responsáveis por atender às demandas apresentadas pela população indígena brasileira de 896,9 mil índios, de 305 etnias com características específicas, segundo o último Censo do Instituto Brasileiro de Geografia e Estatística (IBGE, 2010).

Desde o ano de 2006, o SUAS vem estruturando os CRAS para que possam atender às demandas dos povos indígenas, e são instalados em territórios que apresentam maior vulnerabilidade social. Cabe destacar aqui que os CRAS 
indígenas somente estão instalados em territórios demarcados, ou seja, longe das terras indígenas que apresentam maior vulnerabilidade social e demandas por benefícios, por estarem em territórios não demarcados e para estes cabe a busca para atendimento nos equipamentos mais próximos de suas comunidades.

Diante da diversidade de etnias, modos de vida e demandas, é preciso que os profissionais dessa área compreendam que as comunidades indígenas têm singularidades que são próprias da cultura do território. Nesse sentido, sendo o CRAS uma unidade pública estatal com base territorial, muitas vezes atuarão diretamente com as demandas de populações quilombolas, ciganos, terreiros, ribeirinhos, faxinalenses, caiçaras, entre outros. É preciso conhecer as diferentes realidades e identidades.

Sobre os serviços ofertados nos CRAS Indígenas, tem-se o Serviço de Proteção e Atendimento Integral às Famílias (PAIF) que tem por objetivo identificar as demandas das famílias no território e dentro das comunidades indígenas com olhar diferenciado no sentido de observar se existe ou não escola indígena, unidade de saúde ou visita de profissionais da área, sobre as demandas habitacionais, formas de subsistência, alimentação etc. O mesmo serviço é oferecido no CRAS não indígena, podendo ser acessado por qualquer família que dele necessitar. No entanto, o CRAS indígena, inserido dentro da mesma realidade na comunidade indígena, apresenta uma dinamicidade mais efetiva na prestação dos serviços e identificação das demandas.

Outro serviço oferecido no CRAS é o Serviço de Convivência e Fortalecimento de Vínculos (SCFV), ainda recente dentro da assistência social, que tem como proposta desenvolver ações de caráter preventivo e proativo na defesa e afirmação de direitos e no desenvolvimento de capacidades e potencialidades dos usuários, promovendo alternativas de emancipação para o enfrentamento das vulnerabilidades sociais. Deve ser ofertado de modo a garantir as seguranças de acolhida e de convívio familiar e comunitário, além de estimular o desenvolvimento da autonomia dos usuários (BRASIL, 2016).

O trabalho nos grupos, divididos por faixa etária, é planejado de forma coletiva, com a participação ativa do técnico de referência, dos orientadores sociais e dos usuários do serviço, estimulando trocas culturais e o compartilhamento de vivências, além de desenvolver com os usuários a ideia de pertencimento e afirmação da identidade e fortalecer os vínculos familiares, sempre sob a perspectiva de incentivar a socialização e a convivência familiar e comunitária. 
Esse serviço dentro de uma comunidade indígena, com profissionais éticos e capacitados, é de extrema importância, principalmente em comunidades onde existem escolas indígenas que preservam principalmente a língua materna, além de todos os outros aspectos culturais de cada povo. O SCVF deve potencializar a afirmação cultural desses grupos, a identidade, as tradições e os valores que são transmitidos entre as gerações.

Assim, o que precisa ser diferenciado no atendimento às populações indígenas é a abordagem, a metodologia e as questões, no sentido de compreender que a principal demanda dos povos indígenas é sobre a terra. É preciso que todos os serviços possam reafirmar o direito ao acesso à terra, para as comunidades que ainda se encontram em territórios não demarcados. Além da condição territorial, existe ainda a problemática da falta de documentação que consequentemente influencia no acesso aos serviços da assistência social.

A documentação é parte importante no processo de conquista de autonomia dos indígenas. São sujeitos que têm direito e ter documentos permite que tenham acesso a esses direitos, do contrário, são realizadas ações de modo tutelar e paliativo, restringindo essa autonomia dos povos.

Para que qualquer pessoa que tenha necessidade de acessar algum benefício de transferência de renda é preciso que realize o Cadastro Único, instrumento que tem por objetivo identificar quais são as famílias que apresentam demandas no território de abrangência do CRAS. Além disso, é durante o cadastro que se verifica as vulnerabilidades sociais relacionadas a habitação, saneamento, alimentação, renda etc.

Nos CRAS que atendem famílias indígenas e não indígenas, muitas vezes a maior concentração de pobreza está nas famílias identificadas como indígenas, justamente por estarem em territórios não demarcados.

Outro ponto importante a ser destacado no atendimento aos indígenas é sobre o processo de capacitação dos(as) profissionais da assistência social. Existe um programa nacional de capacitação chamado de CapacitaSuas. No entanto, as orientações possuem um caráter genérico, e apenas alguns materiais informativos, como cartilhas onde se recomenda aos profissionais:

consciência crítica e espírito pesquisador por parte dos profissionais do CRAS acerca da realidade indígena local; equipe de referência multidisciplinar, que deve contar com antropólogo e/ou indigenista experiente e/ou com assessoria antropológica; adoção de abordagem e procedimentos metodológicos pautados no diálogo e no respeito 
intercultural; conhecimento do território (potencialidades, recursos, vulnerabilidades) e da cultura (tradições, organização social e parentesco, visão de mundo) do(s) povo(s) indígena(s) que ali habita(m); planejamento e análise das ações desenvolvidas; promoção da participação dos indígenas no planejamento e avaliação das ações do PAIF (BRASIL, 2016, p. 42)

Sendo o Sistema Único de Assistência Social descentralizado, têm reponsabilidade a União, os estados e os municípios e a orientação é de que o diálogo com as comunidades indígenas seja realizado com a representação governamental mais próxima da realidade. A Comissão Intergestores Tripartite (três esferas de governo) vem trabalhando com a formulação do Plano Decenal da Assistência Social, com o objetivo de pensar em uma dinâmica de atendimento dos serviços, interagindo de modo mais eficaz com as demandas locais em cada território.

De acordo com Ieda Castro, secretária nacional de Assistência Social do Ministério do Desenvolvimento Social e Combate à Fome (MDS, 2016), 8,7 mil índios acessam os serviços da assistência social, mas esse nosso número poderia ser muito maior, tendo em vista que a população indígena brasileira é de 896,9 mil, e 42,3\% de todo esse contingente vivem em terras não demarcadas, em maior vulnerabilidade social. Isso significa que a busca ativa, ferramenta importante para o trabalho do assistente social precisa ser mais efetiva.

As equipes das unidades que atendem dentro e fora das comunidades indígenas precisam estar preparadas para fazer a leitura dessas diferentes realidades, conhecer as particularidades que compõem os territórios e construir estratégias em conjunto com a comunidade. É importante que haja integração entre políticas sociais, assistência social e saúde, sendo que a educação tem um papel fundamental nesse processo.

Outro benefício garantido pela Política de Assistência Social que pode ser acessado pelos indígenas é o Benefício de Prestação Continuada (BPC) para idosos e pessoas com deficiência. $\mathrm{O}$ (a) idoso(a) deve comprovar que tem 65 anos de idade ou mais, que não recebe nenhum benefício previdenciário, ou de outro regime de previdência e que a renda mensal familiar per capita seja inferior a $1 / 4$ do salário mínimo vigente. A pessoa com deficiência deve comprovar que a renda mensal do grupo familiar per capita seja inferior a 1/4 do salário mínimo, devendo também ser avaliado se a sua deficiência o incapacita para a vida independente e para o trabalho; avaliação esta que é realizada pelo Serviço Social e pela Perícia Médica do INSS. 
Além disso, a Assistência Social atua por meio do Programa de Atenção Integral à Família (PAIF), do Benefício de Prestação Continuada (BPC), do Programa de Erradicação do Trabalho Infantil (PETI), que são desenvolvidos no Centro de Referência da Assistência Social (CRAS).

Diante da busca pela consolidação da política de assistência social para os povos indígenas, é necessário que se construa um permanente diálogo com esses usuários. É preciso compreender as especificidades das comunidades indígenas através das suas diferentes formas de organização social, o que implica em ter que qualificar melhor a equipe técnica (incluindo profissionais de antropologia nas equipes) para uma melhor intervenção com esses grupos, buscando sempre promover a inclusão através do conhecimento, sem fragilizar seus valores éticos e culturais de grande complexidade, como descrito no Relatório do GT Indígena:

O cuidado no sentido de promover o respeito a valores culturais e a práticas sociais distintas, evitando intervenções que fragilizem a regulação social tradicional destas comunidades, exige um amplo trabalho de qualificação técnica da intervenção, assim como uma adequada capacitação e composição técnica (BRASIL, 2007, s. p.).

Todas as ações delineadas devem ser fruto do diálogo com esses povos. É necessário que haja respeito à autonomia das comunidades indígenas e consulta às suas demandas, garantindo assim que a política da assistência social seja eficaz para os povos indígenas.

A assistência social tem a oportunidade de melhorar, mas como o nosso povo quer. Branco escreve. Mas o Guarani vai adiante. Vocês só acompanham. Vocês que fizeram as leis e não o índio. Por isso vocês precisam explicar a lei, que a comunidade fica sabendo. A comunidade precisa saber. Também precisa falar com as famílias. [...] A assistência social não tem que dar o remédio e o alimento. É importante que entenda o que é vida para o Guarani. Será que é comida? Onde se prepara os alimentos? O alimento é a alegria, a felicidade, a paz, a energia do povo. Os povos indígenas sabem como agir. Não se pode fazer uma política sozinho, mas frente a frente. Mas também é necessário pedir o principal, que é a demarcação das terras (BRASIL, 2002, p.18).

A atuação do profissional assistente social (em conjunto com equipe multidisciplinar) precisa distinguir-se de todas as outras práticas autoritárias e clientelistas desenvolvidas e direcionadas aos povos indígenas. Nesse sentido, Yazbek (2009) destaca a contribuição dos(as) profissionais: 
Os assistentes sociais vêm, e muito, contribuindo, nas últimas décadas, para a construção de uma cultura do direito e da cidadania, resistindo ao conservadorismo e considerando as políticas sociais como possibilidades concretas de construção de direitos e iniciativas de "contra-desmanche" nessa ordem social injusta e desigual (YAZBEK, 2009, p. 161).

A relação do Serviço Social, da prática do(a) profissional direcionada às demandas indígenas, precisa estar embasada nos princípios do Código de Ética do(a) Assistente Social e nos marcos declaratórios de direitos humanos.

reconhecimento da liberdade como valor ético central e das demandas políticas a ela inerentes - autonomia, emancipação e plena expansão dos indivíduos sociais; a defesa intransigente dos direitos humanos e recusa do arbítrio e do autoritarismo e o empenho na eliminação de todas as formas de preconceito, incentivando o respeito à diversidade, à participação de grupos socialmente discriminados e à discussão das diferenças; construção de uma nova ordem societária, sem dominação exploração de classe, etnia e gênero (CONSELHO FEDERAL DE SERVIÇO SOCIAL, 1993, p.23)

São os princípios do Código de Ética Profissional do Assistente Social que direcionam as ações desses profissionais e determinam o direcionamento da prática por meio de projeto ético-político, construído e avaliado coletivamente pela categoria profissional. Pensar a prática desse profissional dentro de uma sociedade dividida por classe revela seu direcionamento político e seus interesses para a construção de um novo projeto societário ou a manutenção do atual projeto.

Não há dúvidas de que o projeto ético-político do Serviço Social brasileiro está vinculado a um projeto de transformação da sociedade. Essa vinculação se dá pela própria exigência que a dimensão política da intervenção profissional põe. Ao atuarmos no movimento contraditório das classes, acabamos por imprimir uma direção social às nossas ações profissionais que favorecem a um ou a outro projeto societário (BRAZ; TEIXEIRA, 2009, p. 189).

O Serviço Social, ao atuar na garantia dos direitos da classe trabalhadora e das populações tradicionais, posiciona-se contrário ao atual projeto de sociedade desigual e a todas as práticas que retiram os direitos já conquistados por esses sujeitos. No entanto, esse profissional encontra desafios e limites na sua atuação.

De acordo com Raichelis (2009, p. 383), "trata-se de uma dinâmica societária que atinge as diferentes profissões, e também o Serviço Social, que tem nas políticas sociais seu campo de intervenção privilegiado". Nesse sentido, a autora destaca a necessidade de recuperar o trabalho de base junto à população, na busca da consolidação democrática dos direitos: 
O Serviço Social tem uma rica trajetória de trabalho direito com a população e proximidade com seu modo de vida cotidiano. [...] Sem abandonar os espaços institucionais como Conselhos e Conferências, é preciso extrapolá-los e combiná-los com outros mecanismos de ação coletiva, capazes de impulsionar a participação popular em múltiplos espaços onde possam manifestar suas visões, expectativas, necessidades e reivindicações (RAICHELIS, 2009, p. 389-390).

Assim, na atuação direta com os povos indígenas, é necessário incluir o debate sobre a diversidade cultural dos povos e a participação indígena na formulação das políticas a eles aplicadas, valorizando-os como sujeitos autônomos neste processo, viabilizando ao Serviço Social identificar as reais necessidades indígenas e construir uma atuação mais condizente para a emancipação desses povos. Referindo-se à realidade indígena, o grande desafio para os profissionais consiste em praticar, de modo permanente, o método da reflexão, da vivência e da compreensão, para acompanhar e apreender a totalidade das relações complexas e as vinculações do movimento histórico vivenciado pelas diversas etnias.

É necessário avaliar as ações desenvolvidas, os determinantes sociais, culturais, econômicos e políticos que poderão afetar a organização e o modo de vida dos povos indígenas. Afinal, esses sujeitos lutam para assegurar um modo de vida com outra temporalidade, identificados pelas tradições culturais e pelas forças da natureza que demarcam práticas e crenças. Paulo Netto (2009) destaca a importância de buscar permanentemente o conhecimento existente no espaço que o(a) profissional ocupa, assinalando que:

Ao profissional cabe apropriar- se criticamente do conhecimento existente sobre o problema específico com o qual ele se ocupa. É necessário dominar a bibliografia teórica (em suas diversas tendências e correntes, e as suas principais polêmicas), a documentação legal, a sistematização das experiências, as modalidades das intervenções institucionais e instituintes, as formas e organização de controle social, o papel e os interesses dos usuários e dos sujeitos coletivos envolvidos etc. Também é importante, neste passo, ampliar o conhecimento sobre a instituição/organização na qual o próprio profissional se insere (PAULO NETTO, 2009, p. 694-695).

Diante disso, a formação profissional necessita ser um processo permanente para a qualificação da prática profissional e que será percebido na leitura das particularidades das várias etnias, na apreensão das singularidades e dos movimentos que compõem a totalidade de cada território/espaço e que constituem campos de intervenção das(os) profissionais assistentes sociais. 
Nesse sentido, a formação permanente será basilar para a construção de novos conceitos e novos modelos de intervenção que tenham como suporte os fundamentos de uma dada realidade. Como um modelo de intervenção, pode-se destacar o projeto de extensão "Ações socioambientais em defesa dos direitos dos povos indígenas na aldeia Tekohá Yhovy- município de Guaíra, PR”, com gradual ampliação das ações extensionistas, que será descrito no item a seguir.

\section{AÇÕES SOCIOAMBIENTAIS EM DEFESA DOS DIREITOS DOS POVOS INDÍGENAS NA ALDEIA TEKOHÁ YHOVY, NO MUNICÍPIO DE GUAÍRA-PR}

O povo Guarani sempre ocupou os territórios hoje conhecidos como Argentina, Bolívia, Brasil, Paraguai e Uruguai. A territorialidade para este povo tem características históricas, particulares e dinâmicas, vivida, entendida e usada enquanto parte fundamental de sua rica cultura. Para Schallenberger (2006, p. 33), "um espaço integrado no modo de vida, ou seja, um conjunto de elementos constitutivos da cultura, cuja dimensão é o horizonte possível da circulação dos sujeitos que sempre estão em busca de parentes e da mãe-terra generosa que sustenta a vida".

Para Clastres (1974), o povo Guarani do século XVI ocupava um território vasto em que possuíam aldeias situadas a milhares de quilômetros uma das outras, compartilhando uma mesma organização a partir da unidade linguística, cultural e religiosa. Em seu livro "A sociedade contra o Estado", o autor apresenta um estudo sobre a demografia Guarani, capaz de contabilizar aproximadamente a população "cerca de um milhão e meio de índios Guarani antes da chegada dos brancos. [...] os 150 mil índios de 1730 eram dez vezes mais numerosos dois séculos antes: eles eram um milhão e meio" (CLASTRES, 1974, p. 109-113).

O território é mais do que um simples espaço ocupado ou fonte de sustento, a terra para o Guarani é lugar onde se produz toda a sua cultura, é o lugar de ser Guarani. A terra tradicional ocupada por esse povo é chamada de Tekoha, que significa modo de ser. Parmigiani (2015) descreve que "a palavra tekoha, uma junção semântica do termo teko (modo de ser) com o sufixo verbal há (causa, fim, lugar etc.), pode ser traduzida como: o lugar de moradia das leis, dos costumes, o lugar onde se realiza o modo de ser Guarani” (PARMIGIANI, 2015, p. 147). 
O povo Guarani não se considera dono da terra, nem daquilo que vive nela. Entendem que tudo é dado por Deus e o usufruto da terra deve ser feito de forma equilibrada e com total respeito, e tudo o que fazem é observado pelos deuses e pelos outros Guarani. A terra é geradora da vida, alimenta as plantas e por elas é alimentada, abriga os animais, protege os rios, é fértil e generosa, dadivosa possibilita a partilha da vida, transforma-se em dom. Essa partilha como dom é um elemento de grande significado na cultura do povo Guarani, e que reflete nas práticas culturais, religiosas e na dinâmica social (SCHALLENBERGER, 2006). Existe na cultura Guarani um compromisso com a reciprocidade aos demais, respeito à natureza e todos os seus elementos.

No início do século XVI, início da colonização, o povo Guarani e seu território eram disputados pela coroa espanhola e portuguesa. No ano de 1494, foi assinado o Tratado de Tordesilhas entre essas duas coroas. Esse tratado traçou simbolicamente uma linha que cortava a América em duas partes. A partir desse tratado, passaram a pertencer a coroa espanhola "todas as terras descobertas a ocidente de uma linha tirada de polo a polo, trezentas e setenta léguas a oeste das ilhas de Cabo Verde; e a Portugal as descobertas a leste da mesma linha" (CARVALHO, M., 2013, p. 267).

Os espanhóis estabeleceram-se no interior da região oeste do atual estado do Paraná e iniciaram a fundação das cidades como, por exemplo, a Ciudad Real del Guairá, em 1556. Toda essa região era denominada pelos espanhóis de Província do Guairá ${ }^{2}$ e com a chegada da Companhia de Jesus da Europa, iniciouse, com os jesuítas, a fundação de missões no Guairá, tendo como objetivo a catequização dos indígenas.

De acordo com Meliá (2010), "para los españoles los índios son necessários como mano de obra em las eventuales minas que pudieran aparecer. A falta de minas de minerales, ya que no se encontrará ni hierro ni mucho menos plata no oro, la 'mina' por excelencia será la yerba mate ${ }^{3 " '}$ (MELIÁ, 2010, p. 17). No início de 1628 , os bandeirantes ${ }^{4}$ destruíram as missões jesuíticas e as cidades

O Guairá compreendia a região localizada entre o rio Paraná na vertente oeste, rio Paranapanema ao norte, o Iguaçu ao sul e, a leste, as escarpas do argentino Furnas, região de governança do Paraguai, de colonização espanhola (SBRAVATI, 2009, p. 27).

3 Eram as encomiedas, sistema de produção da erva-mate usado nas províncias espanholas, que tinha como única mão de obra os braços escravos indígenas, e que estava em plena atividade nesse período das missões (CARVALHO, J., 2009, p. 20).

4 As bandeiras eram organizadas por iniciativa de particulares, os bandeirantes, e compostas hierarquicamente por um chefe branco ou mameluco (filho de índio com branco), que comandava os outros integrantes, como religiosos, escravos e indígenas. Os principais objetivos das bandeiras eram: $1^{\circ}$ - combater os invasores estrangeiros; indígenas inimigos e escravos 
espanholas construídas nessa região. As entradas desses bandeirantes tinham como objetivo capturar os Guarani e escravizá-los, assim estendiam também o território português sobre o espanhol. Milhares de índios foram levados para as vilas portuguesas para serem vendidos como escravos. Segundo Schallenberger (2006, p.76), "resultou daí uma progressiva destruição do território simbólico do povo Guarani e a inviabilidade da sua reconstrução a partir da organização do espaço missioneiro".

A guerra entre Paraguai e Brasil, que ocorreu entre 1864-1870, marca outro momento de expulsão dos Guarani de seus territórios, quando não incorporados nos exércitos, fugiam das áreas de conflito buscando proteção em lugares distantes, o que significou abandonar seus territórios com risco de perdê-los, como ocorreu posteriormente. O Parque Nacional do Iguaçu também carrega uma dívida histórica, desde o ano de 1939, quando removeu comunidades inteiras próximas do rio Iguaçu. Um desses relatos pode ser encontrado na tese de doutorado da antropóloga Maria Lúcia Brant Carvalho. No relato de uma indígena de 90 anos de idade decorre o seguinte:

Nasci no Oco’y Jakutinga em 1924. Fui morar na aldeia Guarani em 1934, Morei ali até 1943. Moravam 50 famílias na aldeia Guarani, perto do rio Iguaçu, lá onde hoje é o Parque Nacional do Iguaçu. Teve guerra com os índios para tirar os Guaranis da terra: eu vi, eu vi! Mataram tudo! Jogavam os índios nas Cataratas, abriam a barriga com facão e jogavam depois nas Cataratas! Era para o corpo não boiar, pra afundar! [...] A catarata é cemitério de guarani (CARVALHO, M., 2013, p. 330).

No ano de 1974, com a construção da Usina Hidrelétrica de Itaipu, novas remoções de comunidades indígenas ocorreram. Em 1979 começaram as reinvindicações dos povos indígenas que seguem até os dias de hoje. Na década de 1980, formou-se o lago de Itaipu e sem acordos para as realocações dos indígenas, ocorreram ocupações de terras na região. As críticas atingem a própria Fundação Nacional do Índio (FUNAI) que, por meio de documentos oficiais, ignora a territorialidade, o modo de vida e a cultura do povo Guarani que vivia nessa região, tomando decisões propositadas e prejudiciais. Esses acontecimentos refletem ainda hoje na realidade dos povos indígenas na luta pelo território.

O entendimento deste cenário atual, fruto de um processo histórico aliado à formação profissional embasada na teoria social crítica, compreendida por meio da relação teoria e prática, e do espaço formativo de interdisciplinaridade

quilombolas; $2^{\circ}$ - desbravar os sertões e descobrir ouro e pedras preciosas; $3^{\circ}$ aprisionar mão-de-obra indígena (ARANTES, 2009, p. 81). 
e indissociabilidade entre ensino, pesquisa e extensão, é responsável pela qualificação crítica e se apresenta como um espaço de resistência e fortalecimento do projeto ético-político da profissão.

O espaço da formação profissional possibilita uma aproximação com as demandas apresentadas fora do espaço formativo, mas que também refletem dentro das instituições de ensino. É importante demarcar que essas instituições, dentro da lógica contraditória das relações sociais e dos interesses de classe, por vezes fragilizam e engessam, pelos processos burocráticos e formais, inúmeras ações planejadas (pesquisa/extensão) que podem agregar benefícios à sociedade.

Diante do exposto, destaca-se o projeto de extensão “Ações socioambientais em defesa dos direitos dos povos indígenas na Aldeia Tekohá Yhovy", no município de Guaíra ${ }^{5}$, desenvolvido conjuntamente pelo Programa de Educação Tutorial (PET) do curso de Serviço Social e colaboradores durante os anos de 2014 e 2015, que demonstrou ser um novo espaço de fortalecimento, luta e resistência na defesa de novas possibilidades de avanços.

O projeto de extensão universitário tem contribuído de modo significativo para a formação das(os) estudantes e professores envolvidos, tornando-se assim, num diferencial dentro do processo formativo. Desta forma, por meio das atividades de extensão, o programa insere-se nas mais diversas realidades e, em relação ao projeto já referido, insere-se numa realidade difícil e delicada para os povos indígenas.

No município de Guaíra-PR existem 8 aldeamentos e todos eles encontram inúmeras dificuldades de sobrevivência devido às péssimas condições de vida e pela situação irregular de ocupação dos territórios. De acordo com Niedermayer (2018), a Secretaria Municipal de Assistência Social de Guaíra atende 324 famílias aldeadas e ainda em torno de 30 famílias não aldeadas, somando 1.423 pessoas, entre homens, mulheres e crianças. Tem atuado (via equipamentos assistenciais) no fornecimento de benefício eventual para as famílias cadastradas (cesta básica principalmente, além de benefícios para atendimento à natalidade, funeral,

\footnotetext{
O município de Guaíra (que significa 'lugar de difícil acesso' na língua guarani) situa-se no oeste do estado do Paraná, às margens do rio Paraná e desde os primórdios foi um território pertencente aos povos indígenas, da etnia Guarani, que foram catequizados pelos jesuítas espanhóis e posteriormente dizimados e escravizados pelos portugueses. Hoje, segundo dados do IBGE (2014), a população do município de Guaíra é de 32.394 habitantes no território de $560.485 \mathrm{~km}^{2}$, tendo uma economia girando em torno do setor de serviços, comércio e turismo. De acordo com o censo indígena do IBGE (2010), a população indígena no município de Guaíra é de 454 indivíduos. No entanto, segundo dados dos Relatórios de Visita Técnica do Ministério Público Federal (MPF, 2013), já são mais de 1000 indígenas em 8 aldeamentos no município de Guaíra.
} 
vulnerabilidade temporária e quando houver calamidade pública), Programa Família Paranaense, Projeto Prevenção ao Suicídio para crianças e adolescentes desenvolvido nas aldeias no ano de 2017 e um projeto em uma comunidade com parceria da Itaipu voltada para a agricultura.

O projeto de prevenção do suicídio surge como importante ação no município de Guaíra onde é registrado em média um suicídio por ano principalmente entre adolescentes. De acordo com o Ministério Público Federal, de 2010 até 2015 foram registrados 11 suicídios no município. O MPF afirma que o índice de suicídios por parte dos jovens é enorme ainda mais em meio a essa gritante situação de conflito territorial na qual os indígenas se encontram, em situação de acampamento, sem água potável, saúde e educação de qualidade e pelas ameaças diárias vindas das organizações ruralistas de vários municípios da região.

É importante destacar que nos espaços de Conselhos e Conferências da Assistência Social a participação dos indígenas ainda é residual. Compreendemos as condições reais, concretas dos indígenas, além das contradições que existem nesses espaços. No entanto, a observação que fazemos sobre a importância da participação dos indígenas nos espaços deliberativos é pertinente, tendo em vista que importantes decisões são discutidas e tomadas nos conselhos e conferências. São espaços em que é possível também publicitar as reais condições de vida de suas comunidades, além de exigir que o Estado se posicione frente a essa realidade.

Para os profissionais da Assistência Social a condição do território interfere nas ações planejadas e desenvolvidas, pois ações de fomento e desenvolvimento às atividades rurais poderiam ser desenvolvidas e não o são, pois a terra não é regularizada, e os conflitos são frequentes. A condição irregular das retomadas de território do ponto de vista judicial tem sido motivo de impedimento para que os povos indígenas tenham acesso a vários direitos. Na cidade de Guaíra, as 8 comunidades indígenas vivem em territórios não demarcados. Isso significa que todos os 8 territórios se enquadram na condição do território em relação à atuação da assistência. Diante disso, o Ministério Público Federal tem exigido que, independente da condição territorial, as comunidades precisam ser atendidas. Por exemplo, em relação ao acesso à água, várias comunidades dependem das caixas d'água que são abastecidas com a exigência do MPF, e assim em várias outras situações. Novamente retomamos a centralidade da questão indígena que é o território (NIEDERMAYER, 2018). 
Outro ponto importante a ser destacado sobre a particularidade no município de Guaíra é sobre o trabalho em conjunto com outros órgãos públicos. Existe o diálogo, mas não a atuação concreta. Há ainda muita resistência dos órgãos em trabalhar interligados. Por isso, o grande desafio ainda é o trabalho interdisciplinar entre os órgãos de atendimento às demandas dos povos indígenas. Os diferentes conhecimentos e saberes, além do diálogo com os povos indígenas, são uma possibilidade que deve ser construída para melhor efetividade das ações que são desenvolvidas nas comunidades indígenas. A garantia dos direitos dos povos indígenas ultrapassa questões pontuais e específicas, tendo em vista que o território e a cultura dos povos indígenas se definem pela multiplicidade de um conjunto de elementos.

O projeto de extensão, objeto desse item do artigo, é desenvolvido na comunidade Tekohá Yhovy que foi ocupada no ano de 2009 e se encontra em situação de litígio, resistindo à reintegração de posse. Atualmente são mais de 300 pessoas que moram na aldeia. A ação de reintegração de posse foi movida em fevereiro de 2010 e julgada em março, com decisão que não acolheu o pedido de remoção formulado pelos autores, considerando a necessidade de realizar os estudos demarcatórios e a vulnerabilidade dos indígenas, caso ocorresse a reintegração. Em 2011, no entanto, o juiz substituto, contrariando a decisão anterior, emite intimação no sentido de expropriar os indígenas de sua ocupação. Assim, União, Funai e Ministério Público Federal entram com recurso de modo a tentar reverter a situação. Remetida ao Superior Tribunal de Justiça, a apelação ainda pende de julgamento (COMISSÃO GUARANI YVYRUPA, 2017).

A aproximação aos dados apresentados pelo Ministério Público Federal de Guaíra, diagnosticando a realidade dos indígenas e, por meio do projeto de extensão, com a comunidade Tekohá Yhovy em específico, possibilitou maior apreensão da realidade e das inúmeras dificuldades encontradas pelos indígenas. Os indígenas encontram sérias dificuldades no acesso aos serviços públicos, programas e benefícios. As cestas básicas que deveriam ser distribuídas a cada dois meses, por meio do Programa Brasil sem Miséria, sofrem constantes atrasos na entrega (de até três meses), isso acaba provocando graves consequências, como por exemplo, a desnutrição.

O Programa Bolsa Família, benefício garantido à maioria das famílias, auxilia diante dessa realidade, mas acaba sendo insuficiente quando as cestas atrasam, quando a maioria dos indígenas não consegue emprego na cidade, e quando 
precisam comprar material escolar para as crianças. As próprias condicionalidades exigidas por esses programas dificultam o acesso dos indígenas, rotatividade das famílias, falta de documentação, permanência na escola, enquanto não existe nenhum incentivo e investimento do poder público para a educação dentro da própria aldeia a fim de preservar a língua materna.

O projeto também avançou entre 2015 a 2017 com aprofundamento de estudos sobre direitos humanos dos povos indígenas e do movimento regionalizado de luta do povo Guarani por seus direitos de acesso à terra, cultura e organização social. Ao longo do desenvolvimento das atividades, foi alcançada uma ótima participação dos membros da comunidade indígena nas atividades e também da participação discente nas atividades agendadas. Destacamos a participação interdisciplinar de acadêmicos e docentes envolvidos com cursos de graduação e pós-graduação de diferentes áreas.

Para os povos indígenas também é preciso buscar estratégias para continuar sobrevivendo nessas terras brasileiras e a religião tem sido o grande alicerce na luta diária. O relato da vice-cacique e professora da aldeia Tekohá Yhovy, participante do projeto de extensão em 2014 e 2015, constante no relatório das atividades de 2016, faz a avaliação das dificuldades vivenciadas e em contrapartida, a resistência que a cultura indígena sempre tem demonstrado.

A religião, a cultura sempre foi uma estratégia sem dúvida nenhuma, desde muito tempo atrás até hoje, por mais que nessa região a gente é visto como se nós não fossemos indígenas, nós somos vistos de forma que a gente não sabe mais, não conhecemos mais a nossa religião, a nossa cultura, e, internamente dentro da aldeia é essa estratégia que a gente usa, a gente mantém o nosso cântico, nosso canto, rituais, não somente pra usar como resistência, mas sim é um ritual em favor do planeta terra, porque nós povo Guarani, não é por querer simplesmente brigar, não simplesmente por querem tirar terra que hoje se diz que é dos brancos, dos fazendeiros, mas nós sabemos que a América Latina. Nós somos da terra, nós fomos feitos da terra, nosso corpo é terra, não é que a terra seja nossa, mas os brancos não tem como tirar a gente, não tem como tirar os povos indígenas da terra, porque nos pertencemos a ela (UNIOESTE, 2015, s .p.).

Esse relato demarca a posição dos Guarani, um povo que não recua, mas luta e permanece reivindicando seus direitos. É preciso ouvir essa demanda, assumir o compromisso e junto a eles, lutar por um novo projeto societário. No entanto, afirmamos que a maior responsabilidade em dar respostas a esses sujeitos é do Estado, compreendendo que esse próprio Estado é o maior violador dos direitos da classe trabalhadora e dos grupos tradicionais. 


\section{CONSIDERAÇÕES FINAIS}

Diante disso, devemos também, enquanto sujeitos dessa história, construir valores que tenham por objetivo a emancipação humana e assim alcançar uma nova sociabilidade. Segundo Tonet (2005, p. 144), “este objetivo, a emancipação humana, é sinônimo de liberdade plena e porque, neste momento histórico, é não só uma possibilidade real, mas também uma necessidade imperiosa para a humanidade".

A partir do projeto de extensão da Unioeste, tendo-se como princípio a indissociabilidade entre ensino, pesquisa e extensão, e do arcabouço teórico apreendido durante a formação no curso de Serviço Social, foi possível conhecer e refletir mais profundamente sobre a realidade desse grande povo e assumir o compromisso para que de fato os direitos sejam respeitados em sua universalidade.

No final do ano de 2017, a Universidade Estadual do Oeste do Paraná, por meio da Pró-Reitoria de Extensão (PROEX), criou o Observatório de Direitos Humanos-PR, após intenso trabalho da equipe constituída por extensionistas docentes, discentes e agentes universitários na sua formatação e real alcance das demandas de direitos humanos emergentes.

Por meio deste estudo, afirmamos que a maior e urgente demanda apresentada pelos povos indígenas é a demarcação das terras tradicionalmente ocupadas para a reafirmação das culturas tradicionais/nativas, e isso requer do(a) profissional que atua nesse campo, conhecimentos e práticas que possam reafirmar a necessidade da garantia desse direito originário para que se consiga garantir a universalidade dos direitos dos povos - direitos de todos(as).

Destacamos a importância do trabalho realizado pelos(as) profissionais assistentes sociais diante dessa realidade, enfatizando o compromisso ético, político e formativo permanente assumido pela categoria profissional com a defesa intransigente aos direitos das minorias exploradas e marginalizadas, compreendendo que a questão indígena tem extrema importância nas discussões e debates inseridos na mesma. Devemos assim, como categoria, reafirmar nosso compromisso interventivo com esses povos, que sob o interpretar dos fundamentos históricos da política social na América Latina, estiveram envolvidos no expressivo rebaixamento da condição humana (indígenas, negros e os próprios brancos colonizadores e colonizados da América), na luta social por uma sociedade mais igualitária e menos excludente, livre de todas as formas de opressão e exploração. 
A América Latina, por sua longa história, na gangorra da subordinação interna e externa, persistiu e reitera em contextos sociais, institucionais e legais marcados por danos à expressiva maioria de sua população. Avanços e desafios são postos assim às políticas sociais e a outros meios, intervenções profissionais e coletivas que rompam com a herança colonial e com as condições que amarguram a existência e reiteram a miséria, com a ordem e os poderes que roubam a vida e a liberdade de vivê-la com plenitude e dignidade.

\section{REFERÊNCIAS}

ARANTES, A. Í. do B. Bandeiras e bandeirantes. In: SECRETARIA DE ESTADO DA CULTURA (Org.). Missões Conquistando almas e territórios. Curitiba: Secretaria de Estado de Cultura, 2009. p. 81-119.

BRASIL. Secretaria do Trabalho, Cidadania e Assistência Social do Rio Grande do Sul. Povos Indígenas e Políticas Públicas na Assistência Social no Rio Grande do Sul: Subsídios para a construção de políticas públicas diferenciadas às Comunidades Kaingang e Guarani. Porto Alegre: STCAS, 2001-2002, p. 18. (Org.: Lúcio Roberto Schwingel)

BRASIL. Ministério do Desenvolvimento Social e Combate à Fome; Conselho Nacional de Assistência Social. Relatório GT Povos Indígenas, Brasília: MDS, 2007.

BRASIL. Ministério do Desenvolvimento Social e Combate à Fome. Trabalho social com famílias indígenas Proteção Social Básica para uma oferta culturalmente adequada. Brasília: MDS, 2016. Disponível em: https:/ conpas. cfp.org.br/wp-content/uploads/sites/8/2014/11/Orientacoes'Tecnicas_ TrabalhoSocialcomFamiliasIndigenas.pdf. Acesso em: 17 jan. 2017.

BRAZ, M.; TEIXEIRA, J. B. O projeto ético-político do Serviço Social In: CONSELHO FEDERAL DE SERVIÇO SOCIAL (Org.). Serviço Social: direitos sociais e competências profissionais. Brasília: CFESS/ABEPSS, 2009. p. 189-200.

CARVALHO, J. L. Os Guarani. In: SECRETARIA DE ESTADO DA CULTURA (Org.). Missões conquistando almas e territórios. Curitiba: Secretaria de Estado de Cultura, 2009. p. 14-20. 
CARVALHO, M. L. B. de. Das terras dos índios a índios sem terra. O estado e os índios Guarani no Oco’y: violência, silêncio e luta. 2013. 835f. Tese (Doutorado em Geografia Humana) - Faculdade de Filosofia, Letras e Ciências Humanas, Universidade de São Paulo, São Paulo, 2013. Disponível em: www.teses.usp.br/ teses/.../8/.../2013_MariaLuciaBrantDeCarvalho.pdf. Acesso em: 22 dez. 2015.

CLASTRES, P. A sociedade contra o Estado: pesquisas de antropologia política. São Paulo: Cosac Naify, 1974. p. 109-113.

COMISSÃO GUARANI YVYRUPA. Relatório sobre violações de direitos humanos contra os Avá Guarani no oeste do Paraná. Guaíra- PR: CGY, 2017. CONSELHO FEDERAL DE SERVIÇO SOCIAL. Código de Ética Profissional do Assistente Sociai. Resolução CFESS No 273 de março de 1993. Brasília: CFESS, 1993. Disponível em: http://www.cfess.org.br/arquivos/CEP_CFESSSITE.pdf. Acesso em: 12 jan. 2016.

FUNAI. Direitos sociais. Brasília: FUNAI, 2013. Disponível em: http:/ /www. funai.gov.br/index.php/nossas-acoes/direitos-sociais. Acesso em: 19 dez. 2015.

FUNAI. Conferência Indigenista 2015. Brasília: FUNAI, 2015. Disponível em: www.conferenciaindigenista.funai.gov.br. Acesso em: 22 dez. 2015.

FUNAI. Fundação Nacional do Índio. Política Indigenista no Brasil: avanços e desafios. Brasília: FUNAI, s/d. 21 p.

IBGE - INSTITUTO BRASILEIRO DE GEOGRAFIA E ESTATÍSTICA. Indígenas. Brasília: IBGE, 2010. Disponível em: https://indigenas.ibge.gov. br/. Acesso em: 12 jan. 2016.

IBGE - INSTITUTO BRASILEIRO DE GEOGRAFIA E ESTATÍSTICA. Guaíra. Brasília: IBGE, 2014. Disponível em: https://cidades.ibge.gov.br/ brasil/pr/guaira/panorama\&gt. Acesso em: 12 jan. 2016.

MARÉS, C. Os povos indígenas e o direito brasileiro. In: SOUZA FILHO, Carlos Frederico Marés de; BERGOLD, Raul Cezar (Orgs.). Os direitos dos povos indígenas no Brasil: desafios no século XXI. Curitiba: Ed. Letra da Lei, 2013. p. 13-34.

MELIÁ, B. Los índios Guaraníes del Guairá em torno de Ciudad Real. In: SCHALLENBERGER, E. (Org.). Fronteiras culturais e desenvolvimento regional: novas visibilidades. Porto Alegre: Ed. Evangraf, 2010. p. 11-29. 
MPF. Procuradoria da República no Município de Guaíra. Relatório de Visita Técnica à Aldeia Tekohá Yhovy. Guairá: MPF, 2013. Disponível em: http:// www.prpr.mpf.gov.br/pdfs/2013/YHVY.pdf. Acesso em: 11 nov. 2015.

NIEDERMAYER, N. R. As políticas indigenistas no Brasil: um estudo de caso sobre o atendimento das demandas do povo guarani no município de Guaíra-PR. 2018. Dissertação (Mestrado em Desenvolvimento Rural Sustentável) - Programa de Pós-Graduação em Desenvolvimento Rural Sustentável, Universidade Estadual do Oeste do Paraná, 2018.

PAULO NETTTO, J. Transformações societárias e serviço social - Notas para uma análise prospectiva da profissão no Brasil. Rev. Serviço Social e Sociedade, São Paulo, n. 5, ano XVII, abr. 1996.

PAULO NETTOO, J. Introdução ao método na teoria social. In: CONSELHO FEDERAL DE SERVIÇO SOCIAL (Org.). Serviço Social: direitos sociais e competências profissionais. Brasília: CFESS/ABEPSS, 2009. p. 667-700.

PARMIGIANI, J. Território e espaço: a construção da territorialidade Guarani. In: COLOGNESE, Silvio Antonio (Org.). Além das fronteiras sociológicas. Uma agenda para o ensino das Ciências Sociais. Paraná: Evangraf, 2015. p. 141-153.

RAICHELIS, R. O trabalho do assistente social na esfera estatal. In: CONSELHO FEDERAL DE SERVIÇO SOCIAL (Org.). Serviço Social: direitos sociais e competências profissionais. Brasília, CFESS/ABEPSS. 2009. p. 389-390.

SBRAVATI, M. O território natural do Guairá. In: SECRETARIA DE ESTADO DA CULTURA (Org.). Missões conquistando almas e territórios. Curitiba: Secretaria de Estado de Cultura, 2009. p. 27-48.

SCHALLENBERGER, E. Guairá e o espaço missioneiro. Índios e jesuítas no tempo das missões rio-platense. Cascavel: Coluna do Saber, 2006. p. 33.

TERENA, M. O movimento indigenista como voz de resistência. In: VENTURI, G.; BOKANY, V. (Orgs.). Indígenas no Brasil: demandas dos povos e percepções da opinião pública. São Paulo: Ed. Fundação Perseu Abramo, 2013. p. 49- 64. 
TONET, I. Educação e emancipação humana. In: TONET, I. (Org.). Educação, cidadania e emancipação humana. Ijuí: Unijuí, 2005. p. 127-159.

UNIOESTE. Ações Sociambientais em Defesa dos Direitos dos Povos Indígenas: a Comunidade Indígena Tekohá Yhovy no Município de Guaíra-PR. Coordenadora Marli Renate von Borstel Roesler. Toledo: UNIOESTE, 2015.

YAZBEK, M. C. Fundamentos históricos e teórico-metodológicos do Serviço Social. In: CONSELHO FEDERAL DE SERVIÇO SOCIAL (Org.). Serviço Social: direitos sociais e competências profissionais. Brasília: CFESS/ABEPSS, 2009, p. 143-164.

Texto submetido à Revista em 02.08.2018

Aceito para publicação em 15.02.2019 
